\title{
COMPARISON OF ROOT RESORPTION PATTERN IN HUMAN PRIMARY TEETH UNDER PHYSIOLOGIC AND COEXISTENT PATHOLOGICAL CONDITIONS
}

\author{
Gihan S. Hassan * , Dalia H Zahran** and Reda G Saleh***
}

\begin{abstract}
Background: Primary teeth are excellent model to figure out the differences in morphological and histological features of tooth resorption. They may be exfoliated due to physiological resorption of their roots or the coexistent physiological and pathological resorption that are usually observed in the replacement period of dentition.
\end{abstract}

Aim: The aim of this study was to evaluate the qualitative differences in the appearance of the roots of primary teeth undergoing physiological or coexistent physiological and pathological root resorption.

Material and Methods: Twenty primary teeth were examined, Ten exfoliated teeth with physiological resorption represented Group I and ten extracted teeth with coexistent physiological and pathological resorption represented Group II.

Results: At light microscopic examination, group I showed deep round wave like resorption fossae filled with many odontoclasts, and the pulp showed inflammatory cell infiltration along with areas of dystrophic calcification. The odontoblasts were disorganized or disappear completely. Repair by cementum like tissue deposition was found internally. SEM examination revealed variable sized numerous resorption lacunae with smooth edges that had a circular or polygonal shape. Group II showed irregular resorbed root surface and various size odontoclasts besides thick granulation tissue. The pulp was degenerated, necrotic and contained calcification globules. The odontoblastic layer couldn't be identified. Cementum repair was evident externally but at the internal resorption surface. By SEM, the resorption fossae were smaller and irregular in shape with thinner edges.

Conclusion: There were various morphological differences between physiological and coexistent physiological and pathological resorption of human primary teeth

Keywords: Human Primary teeth, Pathological Root resorption, Physiological Root resorption, Scanning Electron microscope.

\footnotetext{
* Lecturer of Oral Biology, Faculty of Dentistry, Tanta University, Egypt. Faculty of Dentistry, El-Giesh St., Tanta, Gharbia, Egypt. ** Ass. Prof. of Oral Biology, Faculty of Dentistry, Tanta University, Egypt. Faculty of Dentistry, El-Giesh St., Tanta, Gharbia, Egypt. *** Lecturer of Oral Biology, Faculty of Dentistry, Tanta University, Egypt. Faculty of Dentistry, El-Giesh St., Tanta, Gharbia, Egypt.
} 


\section{INTRODUCTION}

Tooth Resorption is defined as a condition associated with either a physiological or pathological process resulting in loss of dentin, cementum, or bone $^{(1)}$. Resorption of dental hard tissues is achieved by odontoclasts or dentinoclasts; which possess the same ultrastructural features of osteoclasts as they form a clear zone and ruffled border. As well, they have similar histochemical features such as the expression of cathepsin K, cathepsin D, TRAP, MMP-9, $\mathrm{H}^{+}$-ATPase, membrane Type I-MMP expression $^{(2,3)}$. Nevertheless, odontoclasts are smaller cells that have fewer nuclei and form smaller resorption lacunae than the osteoclasts. These cells differentiate from circulating mononuclear progenitor cells in the dental pulp or periodontal ligament forming mononuclear odontoclasts ${ }^{(4)}$ that may fuse increasing the number of their nuclei ${ }^{(5)}$. Odontoclasts are able to resorb the nonmineralized predentine layer exposing the mineralized matrix. Also, they are able to resorb both the organic and inorganic matrix concurrently ${ }^{(6)}$.

Physiological resorption is a normal phenomenon in the life span of primary teeth prior to their shedding. It is a highly differentiated programmed process in which the roots are shortened and resorption of the supporting tissues and the pulp occurs. During active resorption of the roots of primary teeth, the pulp tissue appears normal, at least during the initial stages ${ }^{(7,8)}$. It has been suggested that apoptosis is the main cause of pulp elimination due to the encoded nature of physiological resorption and the absence of the inflammatory reaction ${ }^{(9)}$. Cytokine-producing cells in the dental pulp mediate monocytemacrophage lineage to form odontoclasts, that supports the role of the pulp in the shedding of primary teeth ${ }^{(10)}$. Moreover, the stellate reticulum and the dental follicle of the underlying permanent teeth secrete stimulatory molecules (cytokines and transcription factors) initiate and regulate root resorption of primary teeth ${ }^{(11)}$.
On the other hand, pathological resorption of the teeth does not occur normally. It usually follows pathological conditions such as inflammation of pulp and periodontal tissues, traumatic injuries and pressure ${ }^{(12)}$. According to the location of the pathological resorption, it has been classified into external and internal ${ }^{(13,14)}$. The inflammatory cells release cytokines, complement, or other factors that lead to odontoblastic degeneration (6). Lesions of odotoblasts result in the removal of the superficial unmineralized predentin layer with exposure of the mineralized dentin and differentiation of odontoclasts. This will eventually result in internal resorption. A similar mechanism occurs in external root resorption as a result of substances produced from inflammation of periradicular tissues, eventually leading to removal or mineralization of cementoid layer ${ }^{(15-17)}$. It has been reported that pathological root resorption does not progress continuously and repair at the sites of resorption lacunae might be achieved by cementum deposition ${ }^{(18,19)}$.

Physiological root resorption of primary teeth and the coexistent physiological and pathological root resorption are usually observed in the replacement period of dentition, that is a vital prerequisite for the replacement of primary teeth and the establishment of permanent dentition ${ }^{(20)}$. In addition, the early loss of primary teeth disturbs the stomatognathic system. No previous researches have dealt with the histological and ultrastructural characteristics of the concurrent physiological and pathological resorption of primary teeth nevertheless this type of resorption is highly frequent in the pediatric clinics. Moreover, research in this zone is of pronounced significance, as new knowledge involved in root resorption may allow the development of different therapies, more biological ones, in order to control or prevent resorption, thus preventing early tooth loss and its consequences (21). Therefore, the present study aimed to evaluate the qualitative differences in the appearance of the roots of primary 
teeth undergoing physiological or coexistent physiological and pathological root resorption. This was achieved through histological and scanning electron microscopy (SEM) examinations.

\section{MATERIAL AND METHODS:}

\section{Teeth Collection:}

A total number of 20 human primary teeth were collected from the dental clinics at Faculty of Dentistry, Tanta University. The age range of the patients was 5 to 8 years. They were divided into two groups, Group I (Physiological root resorption group): included 10 teeth that were normally exfoliated due to physiological resorption of their roots. They were caries free and presented no clinical signs or symptoms of pulp pathology. Group II (coexistent physiological and pathological root resorption group): included 10 carious teeth extracted due to impossibility of endodontic treatment. They presented various periapical inflammatory conditions. Radiographically, periradicular radiolucent areas with complete or asymmetric root resorption was emphasized. Permanent tooth eruption stage was evident in the two groups. The research protocol was designed according to the guidelines on human research published by the Research Ethics Committee at Faculty of Dentistry, Tanta University. Approval of the research and a waiver of consent form were obtained from Faculty of Dentistry, Tanta University Research Ethics Committee.

\section{Histological Examination:}

Five teeth from each group were immersed in $10 \%$ buffered paraformaldehyde for 48 hours and then decalcified in $10 \%$ Ethylenediaminetetraacetic acid (EDTA) solution for 4 weeks. Thereafter, teeth were dehydrated and embedded in paraffin. Specimens were sectioned in the axial plane at $5 \mu \mathrm{m}$ thickness and stained with Hematoxylin and Eosin Stain.

\section{SEM examination:}

Five teeth from each group were fixed in a solution containing $2.5 \%$ glutaraldehyde and $2 \%$ paraformaldehyde in $0.1 \mathrm{M}$ phosphate buffer $(\mathrm{pH}$ $7.2-7.4$ ) for $24-48$ hours at $4^{\circ} \mathrm{C}$. Teeth were then rinsed with distilled water and immersed in a $\mathrm{NaOH}$ solution for 3-5 days at room temperature to remove the adherent tissues. After that, they were rinsed with distilled water for $12 \mathrm{~h}$ at $4^{\circ} \mathrm{C}$ and post-fixed in $1 \%$ osmium tetroxide for $2 \mathrm{~h}$ at $4^{\circ} \mathrm{C}$. Specimens were then dehydrated with ascending graded ethanol (70\%, 80\%, 90\%, 95\%, 100\% ethanol) and dried with $\mathrm{CO} 2$ liquid in a critical point dryer or in air. They were mounted on metal stubs, coated with gold/palladium using an ion sputter, and were examined with scanning electron microscope (JSM 5600LV, Jeol, Tokyo, Japan) in EM Unit of Faculty of Medicine, Tanta University.

\section{RESULTS}

\section{Light microscopic examination}

\section{Physiological resorption group}

Light microscopic examination of group I revealed external resorption of the root dentin and cementum apically towards the crown along with internal resorption of the pulp dentin border (Fig. 1.A). The resorption area was demonstrated as deep round wave like resorption fossae. These fossae were filled with numerous mononucleated and multinucleated odontoclasts in their lacunae (Fig. 1.B). Also, the pulp showed infiltration with many inflammatory cells like neutrophils, lymphocytes, and plasma cells along with areas of dystrophic calcification (Fig. 1.C\&D). The internal surface of some teeth presented either preserved or disorganized odontoblasts or in some cases complete disappearance of the odontoblasts. The odontoclasts were either mononucleated or multinucleated within their lacunae with their typical ruffled border (Fig. 1. E\& F). Some multinucleated odontoclasts were attacking the predentin surface. In some 
specimens, odontoclasts migrated away from the resorption fossae and cementoblast-like cells were differentiated and deposited cementum like tissue in the resorption lacuna (Fig. 1. G\&H).

\section{Coexistent physiological and pathological resorp- tion group}

Light microscopic examination of group II revealed irregular root surface adjacent to the lesion (Fig. 2. A). Various sizes of mononucleated and multinucleated odontoclasts in their resorption fossae besides thick granulation tissue were disclosed (Fig. 2. B). At the internal surface of the teeth, the odontoblastic layer was absent and multiple multinucleated odontoclasts with typical ruffled border were detected. Some resorption fossae were occupied with small cementoblast like cells (Fig.2. C). Moreover, the pulp tissue was necrotic and contained calcification globules (Fig.2. D). Some teeth had disturbed epithelial cell rests of Malassez within the granulation tissue (Fig.2. E). In addition, repair of resorption on the resorbed root surface with acellular cementum were observed in some teeth (Fig. 2. F).

\section{Scanning Electron Microscopy}

\section{Physiological resorption group}

SEM examination of root resorption surface of a group I revealed different sized numerous resorption lacunae with smooth edges that had a circular or polygonal shape (Fig. 3. A). Some resorption lacunae illustrated the calcified collagenous matrix of dentin. Examination of the internal surface of the pulp exposed the orifices of dentinal tubules with some preserved odontoblasts (Fig. 3. B).

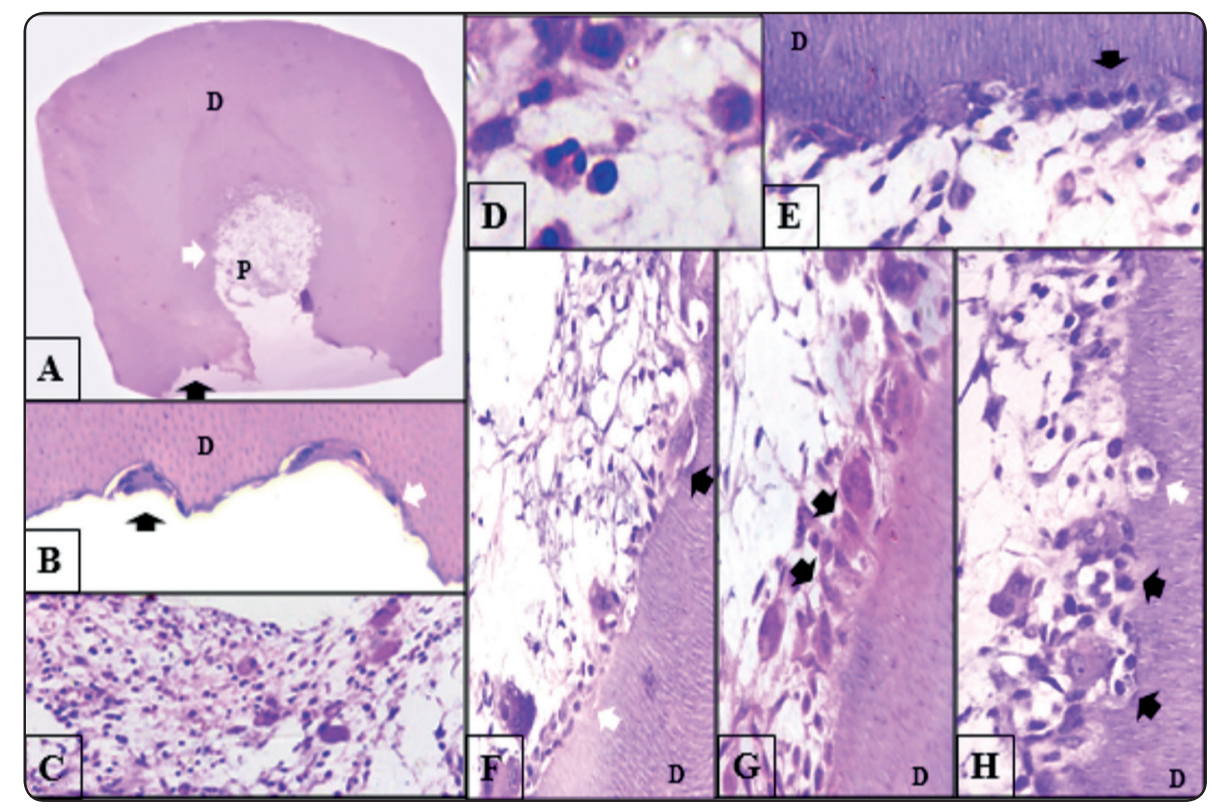

Fig. (1): Light micrographs of exfoliated primary tooth of group I: A. shows large resorption fossae in the surface of root dentine (black arrow) and irregular dentin bordering the pulp (white arrow). B. Higher magnification of the resorption fossae of the root surface showing wave like resorption lacunae with numerous multinucleated (black arrow) along with mononucleated (white arrow) odontoclasts in their lacunae. C. Pulp tissue shows calcification globules. D. Higher magnification of the previous figure showing pulp infiltrated with many inflammatory cells like neutrophils, lymphocytes and plasma cell. E. Light micrograph of the internal surface showing: preserved odontoblasts (white arrow) and multinucleated odontoclasts within their lacunae with their typical ruffled border (black arrows) F. Disorganized odontoblasts (white arrow) and multinucleated odontoclasts (black arrow). G. multinucleated odontoclasts with 3 nuclei attacking the predentin surface in between preserved odontoblasts (black arrows). H. Withdrawal of odontoclasts as well as differentiation of cementoblast like cells and deposition of cementum like tissue in the resorption lacuna (black arrows). One of the cells is imprisoned in the cementum like tissue (white arrow). (H\&E orig. mag., A: ×4, C: ×10, B,E,F,G\&H: ×40, D: ×100). 


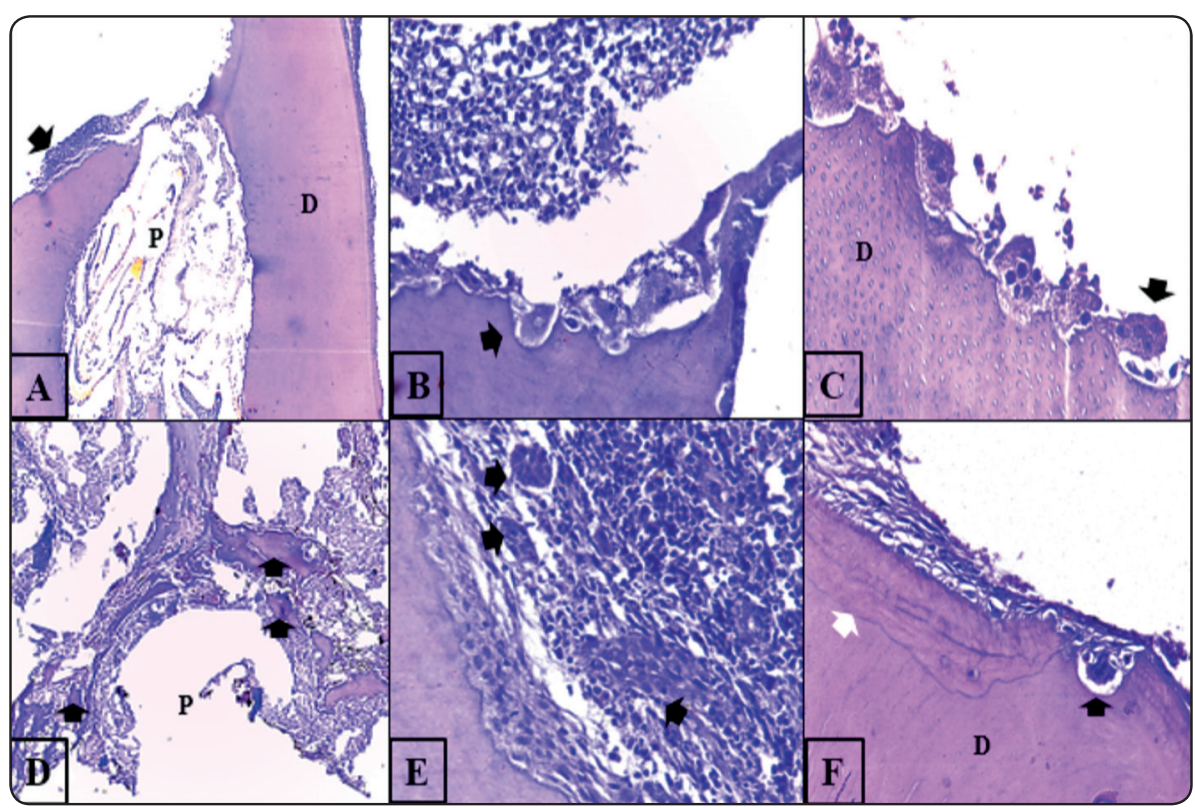

Fig. (2): Light micrographs of extracted primary tooth of group II showing: A: Irregular external root surface adjacent to the lesion (black arrow). B: Higher magnification reveals various sizes of mononucleated and multinucleated odontoclasts in their resorption fossae on the external root surface (black arrow) and thick granulation tissue. C: Higher magnification of the internal surface of the same tooth with multiple multinucleated odontoclasts with typical ruffled border. Also, one resorption fossa (black arrow) is occupied with small cementoblast like cells. D: Calcification globules within necrotic pulp tissue (black arrows). E: another tooth with a resorption fossa harbored with mononuclear cells and granulation tissue containing disturbed epithelial cell rests of Malassez (black arrows). F: Resorption of cementum and dentin which is repaired with cellular cementum followed by layers of acellular cementum (white arrow). Notice, an odontoclast in its lacuna resorbing cementum over the dentinal resorption surface (black arrow) and prominent reversal line. (H\&E orig. mag., A: $\times 4, B, D \& E: \times 10, C \& F: \times 40)$.

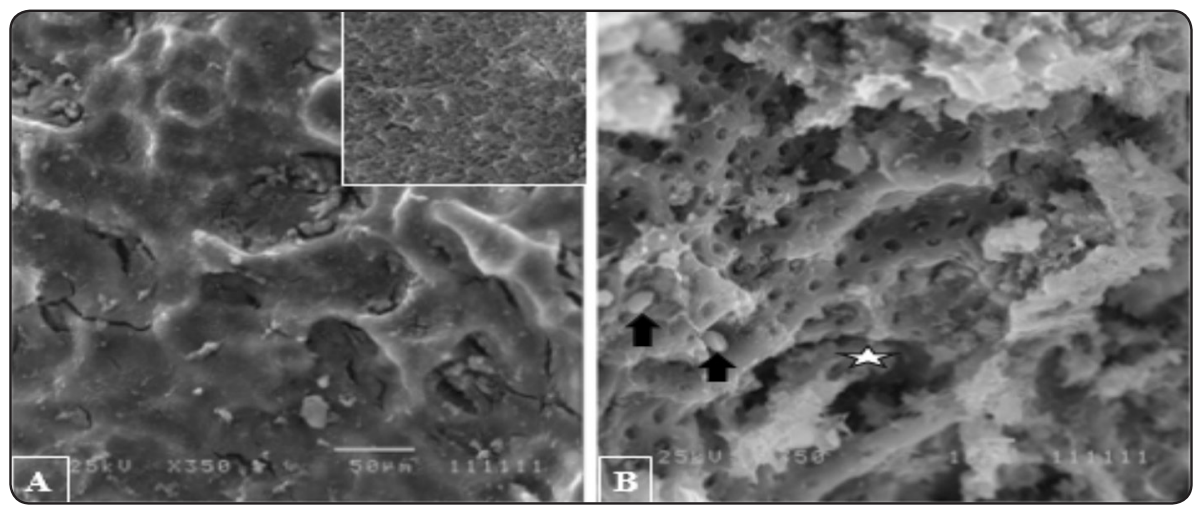

Fig. (3): SEM micrographs of root resorption surface a human exfoliated primary tooth of group I showing: A. different sized numerous resorption lacunae (diameter of 40 to $50 \mu \mathrm{m}$ ) with smooth edges in a circular or polygonal shape. Inset displays a higher magnification (x2000) of the resorption lacunae illustrates the calcified collagenous matrix of dentin. B: shows the internal surface of the pulp exposing the orifices of dentinal tubules with some preserved odontoblasts (arrows) and with an odontoclast in its lacuna (star). Mic. Mag. A: x350, B: x750. 


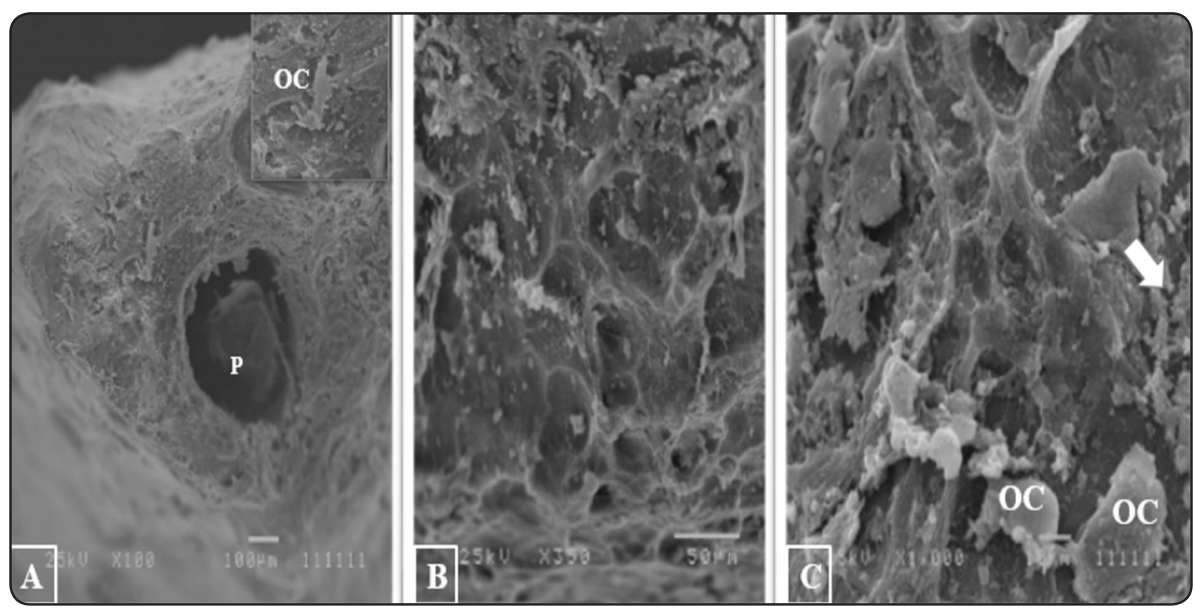

Fig. (4): SEM micrographs of root resorption surface a human extracted primary molar of group II showing: A: irregular rough apical surface of the root. Inset: illustrates odontoclast (OC) in its lacunae. B: higher magnification shows small irregular shape resorption fossae with thinner edges. C: on higher magnification two rounded odontoclasts are observed with many smaller cells filling resorption fossae (arrow). Pulp (P). Mic. Mag. A: x100, B: 350, C: x1000.

Coexistent Physiological and Pathological resorption group

SEM micrographs of pathological root resorption surface of group II showed smaller irregular shape resorption fossae with thinner edges. Some fossae enclosed odontoclasts in their lacunae (Fig. 4. A\&B). Some odontoclasts appeared almost rounded and some resorption fossae were filled with smaller cells (Fig. 4. C).

\section{DISCUSSION}

Primary teeth represent an excellent model to figure out physiological and pathological processes of hard and soft tissues ${ }^{(22)}$. Our results showed that exfoliated primary teeth undergoing physiological resorption demonstrated irregular resorbed root surface apically along with resorption of pulpal surface of coronal and radicular dentin. The resorption process was achieved by numerous mono as well as multi-nucleated cells that were present in their Howships lacunae, in accordance with findings from other studies ${ }^{(23-25)}$. The findings of mononucleated odontoclasts depicted the results of Kim and Choi ${ }^{(26)}$ who suggested that resorption might be induced by mononuclear cells, while Vaes et al. ${ }^{(27)}$ advocated that fusion of the mononuclear cells results in the formation of hard-tissue resorbing cells and initiation of resorption.

It should be mentioned that studies confirmed that in physiological resorption the dental pulp remains in normal conditions, at least initially and does not participate in the process of resorption ${ }^{(9)}$. However, the data presented here demonstrated some changes in the pulp tissue and was in accordance to Bolan and Rocha ${ }^{(25)}$ who confirmed the healthy status of the dental pulp in teeth with physiological root resorption in spite of the presence of hyperemia and dilated blood vessels, various collagen fibers and some foci of dystrophic calcification. The presence of acute and chronic inflammatory cells reported here in group I was in agreement with Bolan and Rocha (25) and might be explained by being in the advanced stage of root resorption. Studies have divided the resorption process to many stages, and most of the exfoliated teeth used in this study had lost more than three quarters of their root lengths. Several studies have confirmed that in the advanced stage where the resorption level has reached nearly $1 \mathrm{~mm}$ below the cementoenamel junction, chronic inflammatory cells infiltrate the dental pulp ${ }^{(8,23,28)}$. In addition, bacterial incursion through the dentogingival junction occurs in the advanced stage of resorption and 
could explain the findings of chronic inflammatory cells in the pulp ${ }^{(9)}$. According to Zhu et al. ${ }^{(29)}$, the internal resorption of the root might occur during physiological resorption of primary teeth as present in group I. Sahara et al. also reported that internal resorption occurs before shedding after the roots had been almost totally resorbed. They related this to the ingress of inflammatory cells of the marginal periodontal tissue into the pulp chamber ${ }^{(28)}$. In this study, the odontoblastic layer is still preserved in some areas, however they were disorganized and some cells were replaced by odontoclasts that can attack the exposed predentin and dentin surfaces.

The physiological root resorption is an intermittent process and throughout the whole process, periods of remodeling and formation of new dental tissues were reported ${ }^{(30)}$. During the periods of rest, new calcific tissues are formed in limited areas on the cementum surface and in the root canals by cementoblasts and/ or osteoblasts $(24,25,31,32)$. Although the physiological role of repair of the resorbed pulpal surface is unknown, It may play a role in helping to preserve the primary teeth until exfoliation ${ }^{(28)}$. In this study, repair by deposition of cementum like tissue was evidenced at the internal resorption site but not found externally. This might be explained by the fact that in the last stage of resorption, just before shedding, the rate of resorption exceeds the formation rate eventually leading to teeth exfoliation.

In the present study, the histological findings of extracted teeth of the coexistent physiological and pathological resorption group in regard to irregular resorption surface, poorly preserved odontobalstic layer, alteration of the pulp tissue, internal and external resorption, and disturbed epithelial cell rests of Malassez were in accordance to previous studies ${ }^{(16,25,33)}$. The alteration of the pulp and presence of granulation tissue were consistent with pathological lesions such as pulp necrosis, abscess, and granuloma and was also reported by Bolan and
Rocha ${ }^{(25)}$. In this study, cementum repair on the external resorbed root surface was observed in group II which was consistent with other studies ${ }^{(34,35)}$. This was different from the result of $\mathrm{Na}$ et al. ${ }^{(36)}$ who reported cementum deposition in physiological resorption but not in pathological resorption caused by periapical inflammation. The authors explained the absence of cementum in the inflammatory root resorption by the fact that root resorption occurred acutely under pathological conditions. The presence of epithelial cell rests of Malssez here was suggested to be related to increased potentiality of cyst development induced by the inflammatory lesion ${ }^{(25,37)}$. Also, Hasegawa et al. ${ }^{(38)}$ observed epithelial cell rests of Malassez in periodontal ligament adjacent to site of the resorption lacunae, and they suggested that epithelial cell rests of Malassez reproduce their potential to secrete and contribute in cementum repair by cementoblast differentiation through epithelial-mesenchymal interactions.

It is worth mentioning that based on the location; the pathological resorption may be internal or external. The internal resorption occurs after damage of the odontoblasts and predentin layer due to chronic pulp inflammation. In this condition, the pulp tissue coronal to the resorption site was necrotic or with chronic inflammation while apically the pulp remained vital providing nutrients for the odontoclast cells and allowing for resorption progression ${ }^{(39,40)}$. On the other hand, the external resorption occurs in carious teeth with infected necrotic pulp and/or in periapical periodontitis. In these conditions progression of resorption depends on the pulp vitality. If the affected tooth remains vital and does not lose its blood supply, resorption will be self-limiting and repair will occur. However, if the entire pulp becomes necrosed, this will eventually limit the resorption ${ }^{(39,41-43)}$.

In our study, the use of SEM in studying root resorption has an advantage over the traditional study methods, as it gave accurate examination 
of the resorbed surfaces and allowed recording the morphology of mineralized tissues in multiple planes which could not be obtained by histological examination only. Also, tilting the mounted specimens in different planes during examination, had made it possible to focus on specific areas of interest. Observation of exfoliated primary teeth of group I under SEM revealed numerous excavated resorption lacunae that were relatively uniform in size and regular in shape and with smooth edges. These observations depicted the observations of $\mathrm{Na}$ et al., and they indicated the uniform slow resorption progress along the entire root surface ${ }^{(36)}$. On the other hand, the resorption lacunae in group II were irregular in shape, smaller in size and had thinner edges when compared to those observed in the physiological group. This implies that resorption progression is rapid and irregular which is the opposite of the physiological process ${ }^{(35)}$. However, these results are different from those observed by $\mathrm{Na}$ et al. ${ }^{(36)}$ who reported that in inflammatory root resorption, the size of the resorption lacunae were larger than that of the physiological resorption.

In conclusion, there were various morphological differences between physiological and coexistent physiological and pathological resorption of human primary teeth. The physiological resorption is a slow process in which the odontoblastic layer was preserved in limited areas, and the pulp tissue showed minimal changes. The deposition of cementum-like tissue was present internally but not on the external resorbed root surface. The resorption lacunae had smooth edges and regular appearance. On the other hand, the coexistent physiological and pathological resorption was characterized by irregular resorption surface, absence of odontoblastic layer and its replacement by numerous odontoclasts. The pulp tissue was degenerated and necrotic with numerous calcific globules. Repair by cementum like tissue was evident externally but not at the internal surface. The resorption lacunae were smaller and irregular with thinner edges than in physiological condition. Although this study had some restricted clinical applications, it might shed light on some topographies thus offering a database for Forensic Dentistry

\section{REFERENCES}

1. Ne RF, Witherspoon DE, Gutmann JL (1999). Tooth resorption. Quintessence Int 30(1), 9-25.

2. Wang Z, McCauley LK. Osteoclasts and odontoclasts: signaling pathways to development and disease (2011). Oral Dis 17(2), 129-42.

3. Babaji P, Devanna R, Jagtap K, Chaurasia VR, Jerry JJ, Choudhury BK, Duhan D. The cell biology and role of resorptive cells in diseases: A review (2017). Ann Afr Med 16(2), 39-45.

4. Wise GE and King GJ (2008). Mechanisms of tooth eruption and orthodontic tooth movement. J Dent Res $87(5), 414-34$.

5. Domon T, Yasuda M, Osanai M, Suzuki R, Takahashi S, Yamamoto T, Wakita M (1998). Increase in odontoclast nuclei number by cell fusion: a three-dimensional reconstruction of cell fusion of human odontoclasts. Anat Rec 252(3), 462-71.

6. Sahara N, Okafuji N, Toyoki A, Ashizawa Y, Deguchi T, Suzuki K (1994). Odontoclastic resorption of the superficial nonmineralized layer of predentine in the shedding of human deciduous teeth. Cell Tissue Res, 277(1):19-26.

7. Rölling I (1981). Histomrphometric analysis of primary teeth during the process of resorption and Shedding. Scand J Dent Res 89(2), 132-42.

8. Eronat C, Eronat N, Aktug M (2002). Histological investigation of physiologically resorping primary teeth using Ag-NOR staining method. Int J Paediatr Dent, 12(3):207-14.

9. Harokopakis-Hajishengallis E (2007). Physiologic root resorption in primary teeth: molecular and histological events. J Oral Sci, 49(1):1-12.

10. Yildirim S, Yapar M, Sermet U, Sener K, Kubar A (2008). The role of dental pulp cells in resorption of deciduous teeth. Oral Surg Oral Med Oral Pathol Oral Radiol Endod, 105(1):113-20.

11. Al-Gburi RM (2012). A Comparative Study for Localization of Odontoclast in Crown and Root of 
Physiological Resorbed Primary Teeth. Tikrit G Dent Sc, 2:96-100.

12. Sreeja R, Minal C, Madhuri T, Swati P, Vijay W (2009). A scanning electron microscopic study of the patterns of external root resorption under different conditions. J Appl Oral Sci, 17(5):481-6.

13. Gunraj MN (1999). Dental root resorption. Oral Surgery, Oral Med Oral Pathol Oral Radiol Endodontology, 88(6):647-53.

14. Consolaro A (2002). Teeth resorptions: in the clinical specialists. 1st ed Mar Dent Press, 203-20.

15. Jerrell RG, Ronk SL (1982). Developmental arrest of a succedaneous tooth following pulpectomy in a primary tooth. J Pedod, 6(4):337-42.

16. Camm JH, Schuler JL (1990). Premature eruption of the premolars. ASDC J Dent Child, 57(2):128-33.

17. Andreasen JO, Andreasen FM (1992). Root resorption following traumatic dental injuries. Proc Finn Dent Soc, 88 Suppl 1:95-114.

18. Coil JA, Sadrian R (1996). Predicting pulpectomy success and its relationship to exfoliation and succedaneous dentition. Pediatr Dent, 18(1): 57-63.

19. ROBERTS JF (2009). Treatment of vital and non-vital primary molar teeth by one-stage formocresol pulpotomy: clinical success and effect upon age at exfoliation. Int $\mathrm{J}$ Paediatr Dent, 6(2):111-5.

20. Wang L, Zhou Z, Chen Y, Yuan S, Du Y, Ju X, Wu L, Wang X (2017). The Alpha 7 Nicotinic Acetylcholine Receptor of Deciduous Dental Pulp Stem Cells Regulates Osteoclastogenesis During Physiological Root Resorption. Stem Cells Dev, 26(16):1186-98.

21. Santos BZ, Mariela M, Cordeiro R (2010). Physiological and pathological factors and mechanisms in the process of root resorption in primary teeth. Rev Sul-Bras Odontol. 2010;7(3):332-9.

22. Benedetto MS De, Siqueira FM, Mascaro MB, Araújo VC, Bönecker MJ (2013). Immunohistochemical expression of biglycan and decorin in the pulp tissue of human primary teeth during resorption. Braz Oral Res, 27(5):438-44.

23. Sasaki T, Shimizu T, Watanabe C, Hiyoshi Y (1990). Cellular roles in physiological root resorption of deciduous teeth in the cat. J Dent Res, 69(1):67-74.

24. Sahara N, Toyoki A, Ashizawa Y, Deguchi T, Suzuki K (1996). Cytodifferentiation of the odontoclast prior to the shedding of human deciduous teeth: An ultrastructural and cytochemical study. Anat Rec, 244(1):33-49.

25. Bolan M and Rocha MJ (2007). Histopathologic study of physiological and pathological resorptions in human primary teeth. Oral Surgery, Oral Med Oral Pathol Oral Radiol Endodontology, 104(5):680-5.

26. Kim JH CB (1993). Scanning electron microscopic observation on the differentiation of odontoclast in the root resorption of human deciduous tooth. J Korean Acad Pediatr Dent, 20:554-75.

27. Vaes G (1988). Cellular biology and biochemical mechanism of bone resorption. A review of recent developments on the formation, activation, and mode of action of osteoclasts. Clin Orthop Relat Res, (231):239-71.

28. Sahara N, Okafuji N, Toyoki a, Suzuki I, Deguchi T, Suzuki K (1992). Odontoclastic resorption at the pulpal surface of coronal dentin prior to the shedding of human deciduous teeth. Arch Histol Cytol, 55(3):273-85.

29. Zhu Y, Shang L, Chen X, Kong X, Liu NA, Bai Y, Fang J, Dang J, Wang X, Jin Y (2013). Deciduous Dental Pulp Stem Cells Are Involved in Osteoclastogenesis During Physiologic Root Resorption, 228(1); 207-15.

30. Prove SA, Symons AL, Meyers IA (1992). Physiological root resorption of primary molars. J Clin Pediatr Dent. 1992;16(3):202-6.

31. Sasaki T, Watanabe C, Shimizu T, Debari K, Segawa K (1990). Possible role of cementoblasts in the resorbant organ of human deciduous teeth during root resorption. J Periodontal Res, 25(3):143-51.

32. Domon T, Osanai M, Yawaka Y, Suzuki R, Takahashi S, Yamamoto T, Wakita M (2000). Ultrastructural study of the root dentine surface resuming resorption on human deciduous teeth. Ann Anat, 182(2):175-84.

33. Wang C-Y, Stashenko P (1991). Kinetics of Bone-resorbing Activity in Developing Periapical Lesions. J Dent Res, 70(10):1362-6.

34. Yawaka Y, Osanai M, Akiyama A, Ninomiya R, Oguchi H (2003). Histological study of deposited cementum in human deciduous teeth with pathological root resorption. Ann Anat, 185(4): 335-41.

35. Park YH, Sohn HK, Choi BJ (2000). Fine Structures Of Physiologic and Pathologic Root Resorption Surfaces of Deciduous Teeth. J Korean Acad Pediatric Dent, 27(4):524-34. 
36. Na H, Son H, Song J, Kim S, Lee J, Choi H, Choi B (2017). Histopathological Observation of Three Types of Root Resorption Surface in Maxillary Primary Incisors. J Korean Acad Pediatr Dent, 44(3): 289-297

37. Myers DR, Battenhouse MR, Barenie JT, McKinney RV, Singh B (1987). Histopathology of furcation lesions associated with pulp degeneration in primary molars. Pediatr Dent, 9(4):279-82.

38. Hasegawa N, Kawaguchi H, Ogawa T, Uchida T, Kurihara H (2003). Immunohistochemical characteristics of epithelial cell rests of Malassez during cementum repair. J Periodontal Res, 38(1):51-6.
39. Patel S, Ford TP (2007). Is the Resorption External or Internal? Dent Update, 34(4):218-29.

40. Patel S, Ricucci D, Durak C, Tay F. Internal Root Resorption: A Review (2010). J Endod, 36(7):1107-21.

41. HAAPASALO M, ENDAL U. Internal inflammatory root resorption: the unknown resorption of the tooth (2006). Endod Top, 14(1):60-79.

42. Trope M (2002). Root Resorption due to Dental Trauma. Endod Top, 1(1):79-100.

43. Heithersay G (2007). Management of tooth resorption. Aust Dent J, 52:S105-21. 